\title{
Adequately Iodized Salt Utilization and Associated Factors among Households in Tach Armachio District, Northwest Ethiopia: A Community-Based Cross-Sectional Study
}

\author{
Worku Mamo, ${ }^{1}$ Terefe Derso, ${ }^{2}$ and Solomon Gedlu Nigatu $\mathbb{D}^{3}$ \\ ${ }^{1}$ Carter Center Ethiopia, Addis Ababa, Ethiopia \\ ${ }^{2}$ Department of Human Nutrition, Institute of Public Health, College of Medicine and Health Sciences, University of Gondar, \\ Gondar, Ethiopia \\ ${ }^{3}$ Department of Epidemiology and Biostatistics, Institute of Public Health, College of Medicine and Health Sciences, \\ University of Gondar, Gondar, Ethiopia \\ Correspondence should be addressed to Solomon Gedlu Nigatu; sol.gondar@gmail.com
}

Received 17 December 2020; Revised 3 April 2021; Accepted 8 April 2021; Published 16 April 2021

Academic Editor: Karen L. Sweazea

Copyright (C) 2021 Worku Mamo et al. This is an open access article distributed under the Creative Commons Attribution License, which permits unrestricted use, distribution, and reproduction in any medium, provided the original work is properly cited.

\begin{abstract}
Background. For the synthesis of thyroid hormones, iodine is a crucial trace element. Iodine deficiency disorders affect all groups particularly: pregnant, young women and children. Iodine deficiency disorder has been recognized as a serious public health issue in Ethiopia. Therefore, this study planned to assess iodized salt utilization and associated factors at the household level. Methods. A community-based cross-sectional study was conducted from January 25 to February 24, 2019, in Tach Armachio district, Northwest Ethiopia. A single population proportion formula was used to calculate the sample size and a total of 555 households were sampled. A multistage sampling technique was conducted to select the household. An iodometric titration method was performed. A structured, pretested, and face-to-face interview questionnaire was used to collect data; then, it was entered in Epi Info 7 and exported to SPSS version 25 for analysis. Bivariable and multivariable analyses were done to identify predictor variables. A $95 \%$ confidence interval and adjusted odd ratio were reported. $P$ values less than 0.05 were considered statistically significant in the multivariable analysis. Results. This study showed that iodized salt was adequately utilized by $61.1 \%(\mathrm{CI}=57 \%-65 \%)$ of households. Good knowledge of iodine deficiency disorder $(\mathrm{AOR}=2.25,95 \% \mathrm{CI}=(1.44,3.50))$, keeping salt in the kitchen house away from fire $(\mathrm{AOR}=5.09,95 \% \mathrm{CI}=(3.25,7.98))$, buying packed salt $[\mathrm{AOR}=1.89,95 \% \mathrm{CI}=(1.12,3.19))$, keeping salt in a covered container $(\mathrm{AOR}=2.18,95 \% \mathrm{CI}=(1.24,3.81)$ ), and exposing salt to sunlight $(\mathrm{AOR}=0.39,95 \% \mathrm{CI}=(0.23,0.65))$ were significantly associated. Conclusion. In the district, adequately iodized salt utilization was low. Therefore, it is necessary to enforce the current law for merchants to sell iodized packed salt and teach the community how to handle it.
\end{abstract}

\section{Introduction}

Iodine is a crucial element for the synthesis of thyroid hormone (TH). This hormone is involved in the body's growth, development, reproduction, and metabolic process control [1]. Iodine deficiency disorders (IDDs) occur when the human body does not receive the recommended amount of iodine on a daily basis. IDDs can result in mental impairment, endemic goiter, hypothyroidism, reproductive failure, and dwarfism [2-4]. Salt iodization is the most cost-effective, widely used, and low-cost public health intervention for delivering the required amount of iodine to the general population [2, 4].

In 2017, less than 10 percent of the global population of the general population lived in countries categorized as iodine deficiency [5]. IDDs affect people of all ages, but young children, women of reproductive age, pregnant women, and lactating women are the most vulnerable [4]. IDDs remain a public health concern [6]. Previous studies in South Asia [7-10] and Sub-Saharan Africa [7, 11-14] have found that iodized salt is in short supply at the household $(\mathrm{HH})$ level. In Ethiopia, pocket-area studies revealed that a 
large number of HHs used insufficiently iodized salt when compared to the universal standard [15-20]. However, according to the 2016 Ethiopian Demographic Health Survey, 89 percent of HHs used enough iodized salt [21].

The use of packed salt, not exposing salt to sunlight, storing salt in dry areas, shorter storage time, adding salt late after cooking, good knowledge of iodized salt and IDDs, and socioeconomic status are all factors that influence the availability of adequately iodized salt [7, 22-26]. Previously, a rapid test kit was used to assess iodine content qualitatively, but it was unreliable (low specificity) [27]. The iodometric titration method (IDTM) is the best and most preferred method. This method is reliable and is used to determine the amount of iodine in salt [28-30].

A good strategy for preventing IDDs is to ensure that the iodine content in salt is safe and sufficient at the $\mathrm{HH}$ level $[29,31]$. It is necessary to pay attention to how such iodine salt should be stored. According to literatus because of the volatile of iodine, it will be lost due to high humidity and boiling during cooking. Even if the effect is small, light or dry heat causes iodine to be lost from the salt [32-34]. There is an inconsistency of findings in Ethiopia, and no studies have been done using the titration method in the current study area. Furthermore, the study area has a high prevalence of goiter, implying that iodized salt utilization will be poor $[35,36]$. Therefore, this study used gold standard IDTM to assess the prevalence of adequately iodized salt usage and associated factors at the $\mathrm{HH}$ level in Tachar Amchio district, Northwest Ethiopia.

\section{Materials and Methods}

2.1. Study Design, Area, and Period. Tach Aramchio district is found in the Central Gondar Zone, Amhara region, Northwest Ethiopia. It is located 790 kilometers north of Addis Ababa and 63 kilometers south of Gondar Town. According to the 2011 Finance and Economic Development Bureau projections, the district had a total of 37,139 households and 162,354 people. The administration is divided into 32 kebeles (the smallest administrative unit of Ethiopia). The elevation ranges from 900 to 1200 meters above sea level. There is one district hospital, nine health centers, and 39 health posts. A community-based crosssectional study was conducted from January 25 to February 24,2019 . The sample size was determined using a single population proportion formula. It accounts for a $33.2 \%$ prevalence [15], 95\% confidence level (CI), 5\% margin of error, and 1.5 design effect. It also included a $10 \%$ nonresponse rate, resulting in a sample size of 563 households. A multistage sampling procedure was used. Eight of the 32 kebeles were chosen by lottery in the first stage (one from the urban area and the other from the rural area). Second, an $\mathrm{HH}$ was chosen using a systematic sampling method, with every $15^{\text {th }} \mathrm{HH}$ included in the study sample.

2.2. Data Collection Tools and Measurement. A structured, pretested, and face-to-face interview questionnaire was used to collect data. The questionnaire included sociodemographic questions, as well as questions about iodized salt and IDD knowledge (study participants who answered correctly $50 \%$ of nine questions about iodized salt and IDD knowledge were considered to have good knowledge, while those who scored below 50\% were considered to have poor knowledge) [22], salt storage condition, and practice variables for handling. Four welltrained health extension workers collected the data.

2.3. Laboratory Procedures. To determine salt iodine content, IDTM was done. A $50 \mathrm{~g}$ mixed (homogenized) salt sample was taken from each systematically selected household, using a moisture-free, clean, and airtight plastic container. The sample was labeled and coded with the date of sampling, source of salt, and batch number. Each sample was analyzed in triplicate, and the average sample concentration was used to calculate the iodine concentration. The IDTM uses reagents like sulphuric acid, potassium iodate, and potassium iodide as principal reagents, standardized sodium thiosulphates (as titrant), and starch solution as an indicator. The titration results were converted to iodine concentrations and then classified based on their iodine content. The outcome variable, adequately iodized salt utilization measured as parts per million (ppm) $<15$ was considered as inadequately iodined, while $\geq 15 \mathrm{ppm}$ is considered as adequately iodized [30]. The test was carried out in an Ethiopian public health institution's laboratory.

2.4. Data Processing and Analysis. Data quality is maintained by ensuring that data is complete and consistent. It was entered into the Epidemiological Information (Epi Info) software version 7.1 and then transferred to Statistical Package for Social Sciences (SPSS) version 16 for analysis. The following calculations were made: mean, standard deviation, percentage, confidence interval, and odds ratio (OR). A principal component analysis was used to determine wealth status. Wealth is a latent variable which cannot measure directly using a single question. There were 15 questions dealing with productive assets, nonproductive assets, and household utilities. We used a factor reduction analysis. Our first step was that variables have been reclassified; we assign categories values with 0 and 1 . Then, we check coefficients, KMO, Bartlett's test of sphericity, and eigenvalues. Finally, we rank the wealth index after ascending and created the quintiles as poor, medium, and rich. Bivariable logistic regression was used to see if there was a significant relationship between the dependent and independent variables. Variables with $P$ values of 0.2 were included in the multivariable analysis during the bivariable analysis. A multivariable analysis was done to control a possible confounding effect of independent variables. In the multivariable analysis, a variable with a $P$ value of less than 0.05 was considered statistically significant. The Hosmer and Lemeshow goodness of fit test for the model was also checked and it had a $P$ value of 0.15 . Multicollinearity among independent variables was checked using the Variance Inflation Factor (VIF) which indicates that there is no 
multicollinearity because all variables have $\mathrm{VIF}<7$ and tolerance greater than 0.1 .

\section{Result}

A total of 555 households were involved in the study and eight $\mathrm{HHs}$ declined to participate which made the response rate $98.57 \%$. The average age of respondents was 33.36 years with standard deviation \pm 9.08 . Almost half of the respondents $270(48.6 \%)$ were between the ages of 34 and 44 . The majority of the study participants $(n=459 ; 82.7 \%)$ were females by sex, and 317 (57.1\%) were housewives by their occupation. Five hundred twenty-two (94.1\%) of the respondents were Orthodox Christians.

Regarding marital status, 442 people (79.6\%) were married. Nearly half of the study subjects' 263 participants $(47.4 \%)$ could read and write. Three hundred and seventyfour $(67.4 \%)$ of the HHS have less than five members. In family wealth status, 206 (37.1\%) were classified as middle income (Table 1).

\subsection{Knowledge of IDD, Storage Condition, and Utilization} Practice of Iodized Salt at Households. The prevalence of adequately iodized salt is found in $61.1 \%$ (95\% CI 57-65) of the study participants, which is $>15 \mathrm{ppm}$. The median iodine content of the sampled salt was $18.03 \mathrm{ppm}$, with an interquartile range of $11.66 \mathrm{ppm}$ to $28.34 \mathrm{ppm}$. The amount of salt in the $15-40 \mathrm{ppm}$ range was $42.2 \%$.

Respondents with good knowledge of IDDs and iodized salt were $312(56.2 \%)$. The majority of study participants ( $n=417 ; 75.1 \%)$ walked less than an hour to buy salt, and two-thirds (77.5\%) did so once a week. Households that purchased it from a retail store and in packed form numbered $312(56.2 \%)$ and $432(77.8 \%)$, respectively.

Almost all of the 545 (98.2\%) HHs stored their salt in a dry place. Of these, $467(84.1 \%)$ kept their salt away from sunlight (Table 2).

\subsection{Associated Factors of Adequate Iodized Salt. When $\mathrm{HH}$} heads with good knowledge of IDD were compared to those with poor knowledge, they were 2.25 times more likely to have adequate iodized salt $(\mathrm{AOR}=2.25,95 \% \mathrm{CI}$ : 1.44-3.50). Respondents who place their salt away from the fire in the kitchen were 5.09 times more likely to have adequately iodized salt compared to those placed near to the fire $(\mathrm{AOR}=5.09,95 \% \mathrm{CI}: 3.25-7.98)$.

The odds ratio of using adequate iodized salt is $89 \%$ higher among those who buy packed salt compared to unpacked salt $(\mathrm{AOR}=1.89,95 \% \mathrm{CI}: 1.12-3.19)$. Study participants who stored their salt in a covered container were 2.18 times more likely to have adequately iodized salt as compared to those who did not $(\mathrm{AOR}=2.18,95 \%$ CI: 1.24-3.81). The odds of adequately iodized salt usage decreased by $61 \%$ among those who exposed their salt to sunlight (AOR $=0.39,95 \%$ CI: 0.23-0.65) (Table 3).

\section{Discussion}

According to the $\mathrm{WHO}$ and International Council for Control of Iodine Deficiency Disorders (ICCIDD) standard, the elimination of IDD will be possible if more than $90 \%$ of the households utilized adequately iodized salt [37]. The current study revealed that $61.1 \%$ of households had adequately iodized salt ( $>15 \mathrm{ppm}$ ), falling short of the universal salt iodization (USI) target of $90 \%$ coverage. This result was lower than those found in studies from Saudi [37], Bangladesh [26], Nepal [38], and Dessie town, Ethiopia [19]. It was, however, higher than the studies of Morocco [39], Sudan [16], and four studies from Ethiopia [17-19, 21]. It is in line with research conducted in Ethiopia's Asella town [40], Dera district [41], and Wondo Genet town [20]. The possible reason for this difference includes the use of IDTM to measure iodine content in the current study, difference in the study population, governments' commitment to enforcing legislation, and regulations on the iodization of salt, distribution, and retail. Ethiopian Food and Drug Authority issued a directive in 2011 to prohibit the distribution and retail of noniodized salt. If the directive is violated, the trade license will be temporarily suspended for one to six months, and in the worst case, the license will be permanently revoked [42].

In this study, the odds of having adequately iodized salt in a household was higher among participants who had good knowledge of IDD and iodized salt utilization than poor knowledge. This finding is supported by the studies in Ghana [23], Bensa woreda [43], Laelay Maychew [23], and Dabat [15], Ethiopia. These could be respondents (households) who are already aware and can easily put their knowledge into practice by purchasing iodized salt.

Households who keep their salt away from the fire in the kitchen were more likely to have adequate iodized salt compared to those that kept their salt near the fire. This could result from heat-induced alteration or depletion of iodine as it is volatile by nature. As a result, the respondents who had placed salt away from the fire and protected it from the heat in the kitchen had adequately iodized salt [44].

$\mathrm{HH}$ s who used packaged salt were more likely to have adequate iodized salt than those who used bulk salt. This finding is supported by the studies done in Bensa woreda [43], Gondar town [22], and Dabat [23]. This may have been packing material that protected the salt from exposure to sunlight and kept it from moisture.

Households that used salt stored in covered containers were positively associated with adequately iodized salt. Salt placed in a covered container was 1.92 times more likely to have adequately iodized salt than salt stored in open containers, and this study is consistent with the studies in Dera and Lalo Assabi district, Ethiopia [41, 45]. The iodine content of the salt may be maintained or retained in the covered container. Also, a covered container prevents salt from being exposed to light and keeps it dry.

At the $\mathrm{HH}$ level, exposing salt to sunlight was found to be inversely related to adequate iodized salt utilization. This finding is consistent with research from Wolita [18], Goba town [46], Dera district [45], and Gondar town [22], 
TABle 1: Sociodemographic and economic characteristics of respondents, Tach Armachiho district, Northwest Ethiopia $2019(N=555)$.

\begin{tabular}{|c|c|c|c|}
\hline Variables & Category's & Frequency $(N)$ & Percentage \\
\hline \multirow{2}{*}{ Sex } & Male & 96 & 17.3 \\
\hline & Female & 459 & 82.7 \\
\hline \multirow{3}{*}{ Age in year } & $17-29$ & 213 & 38.4 \\
\hline & $30-44$ & 270 & 48.6 \\
\hline & $\geq 45$ & 72 & 13 \\
\hline \multirow{2}{*}{ Residence } & Urban & 300 & 54.1 \\
\hline & Rural & 255 & 45.9 \\
\hline \multirow{2}{*}{ Religion } & Orthodox & 522 & 94.1 \\
\hline & Muslim & 33 & 5.9 \\
\hline \multirow{4}{*}{ Marital status } & Single & 50 & 9 \\
\hline & Married & 442 & 79.6 \\
\hline & Divorced & 52 & 9.4 \\
\hline & Widowed & 11 & 2 \\
\hline \multirow{4}{*}{ Educational status of study participant } & Unable to read and write & 108 & 19.4 \\
\hline & Read and write & 263 & 47.4 \\
\hline & Primary & 103 & 18.6 \\
\hline & Secondary and above & 81 & 14.6 \\
\hline \multirow{4}{*}{ Educational status of head of household } & Unable to read and write & 43 & 7.8 \\
\hline & Read and write & 301 & 54.2 \\
\hline & Primary & 100 & 18 \\
\hline & Secondary and above & 111 & 20 \\
\hline \multirow{5}{*}{ Occupation of study participant } & Government employee & 28 & 5.1 \\
\hline & Merchant & 67 & 12.1 \\
\hline & Housewife & 317 & 57.1 \\
\hline & Self-employed & 124 & 22.3 \\
\hline & Others* & 19 & 3.4 \\
\hline \multirow{2}{*}{ Family size in number } & $<5$ & 374 & 67.4 \\
\hline & $\geq 5$ & 181 & 32.6 \\
\hline \multirow{3}{*}{ Wealth status } & Poor & 177 & 31.9 \\
\hline & Medium & 206 & 37.1 \\
\hline & Rich & 172 & 31.0 \\
\hline
\end{tabular}

*Students, daily laborer, childhood and family members.

TABLE 2: Storage condition and utilization practice of iodized salt at household level in Tach Armachiho district, Northwest Ethiopia 2019 $(N=555)$.

\begin{tabular}{|c|c|c|c|}
\hline Variables & Category's & Frequency $(N)$ & Percentage \\
\hline \multirow{2}{*}{ Used of ID salt cooking food } & Yes & 463 & 83.4 \\
\hline & No & 92 & 16.6 \\
\hline \multirow{4}{*}{ Time salt added to cook in the last 24 hours } & Early at the beginning of cooking & 14 & 2.5 \\
\hline & Late in the middle of cooking & 61 & 11.0 \\
\hline & At the end of cooking & 354 & 63.8 \\
\hline & Right after cooking & 126 & 22.7 \\
\hline \multirow{2}{*}{ Storage place in kitchen house } & Near to the fire & 149 & 26.8 \\
\hline & Away from the fire & 406 & 73.2 \\
\hline \multirow{2}{*}{ Used covered container } & Yes & 483 & 87 \\
\hline & No & 72 & 13 \\
\hline \multirow{2}{*}{ Storage container } & Dry place & 545 & 98.2 \\
\hline & Moisture place & 10 & 1.8 \\
\hline \multirow{2}{*}{ Exposed to sunlight } & Yes & 88 & 15.9 \\
\hline & No & 467 & 84.1 \\
\hline \multirow{2}{*}{ Type of salt } & Packed & 432 & 77.8 \\
\hline & Bulk & 123 & 22.2 \\
\hline
\end{tabular}


TABle 2: Continued.

\begin{tabular}{|c|c|c|c|}
\hline Variables & Category's & Frequency $(N)$ & Percentage \\
\hline \multirow{3}{*}{ Where did you buy salt? } & Retail shop & 312 & 56.2 \\
\hline & Open market & 213 & 38.4 \\
\hline & Wholesale & 30 & 5.4 \\
\hline \multirow{2}{*}{ Distance travel to buy salt } & $\leq 1 \mathrm{hr}$ walking on foot & 417 & 75.1 \\
\hline & $>1 \mathrm{hr}$ walking on foot & 138 & 24.9 \\
\hline \multirow{3}{*}{ Frequency of buying salt } & Once a week & 74 & 13.3 \\
\hline & Once a month & 430 & 77.5 \\
\hline & Once in more than a month & 51 & 9.2 \\
\hline \multirow{2}{*}{ Wash salts before consumption } & Yes & 13 & 2.3 \\
\hline & No & 542 & 97.7 \\
\hline \multirow{3}{*}{ Use ID salt to preserve food } & Yes & 180 & 32.4 \\
\hline & No & 176 & 31.7 \\
\hline & I do not remember & 199 & 35.9 \\
\hline \multirow{3}{*}{ Salt iodine content ppm } & $1-14.99$ & 216 & 38.9 \\
\hline & $15-40$ & 234 & 42.2 \\
\hline & $>40$ & 105 & 18.9 \\
\hline
\end{tabular}

TABle 3: Factors associated with adequate iodized salt utilization in Tach Armachiho district, Northwest Ethiopia 2019 ( $N=555)$.

\begin{tabular}{|c|c|c|c|c|c|c|}
\hline \multirow{2}{*}{ Variables } & \multirow{2}{*}{ Categories' } & \multicolumn{2}{|c|}{$\begin{array}{c}\text { Adequate iodized salt } \\
\text { utilization }\end{array}$} & \multicolumn{2}{|c|}{ Odds ratios } & \multirow{2}{*}{$\begin{array}{c}P \\
\text { value }\end{array}$} \\
\hline & & $\begin{array}{c}\text { Yes } \\
(\geq 15 \mathrm{ppm})\end{array}$ & $\begin{array}{c}\text { No } \\
(<15 \mathrm{ppm})\end{array}$ & COR $(95 \% \mathrm{CI})$ & AOR $(95 \% \mathrm{CI})$ & \\
\hline \multirow{2}{*}{ Family size } & $<5$ members & 241 & 133 & $1.54(1.07-2.20)$ & $1.37(0.88-2.12)$ & 0.16 \\
\hline & $\geq 5$ members & 98 & 83 & 1 & 1 & \\
\hline \multirow{2}{*}{ Place of residence } & Urban & 193 & 107 & $1.35(0.96-1.89)$ & $0.63(0.37-1.08)$ & 0.90 \\
\hline & Rural & 146 & 109 & 1 & 1 & \\
\hline \multirow{4}{*}{ Educational status of study participant } & Not educated & 59 & 49 & $0.67(0.37-1.21)$ & $1.36(0.63-2.93)$ & 0.43 \\
\hline & Read and write & 158 & 105 & $0.84(0.50-1.41)$ & $1.23(0.65-2.30)$ & 0.53 \\
\hline & Primary (1-8) & 70 & 33 & $1.18(0.64-2.18)$ & $1.55(0.78-3.11)$ & 0.21 \\
\hline & $\begin{array}{l}\text { Secondary and } \\
\text { above }\end{array}$ & 52 & 29 & 1 & 1 & \\
\hline \multirow{2}{*}{$\begin{array}{l}\text { Knowledge of IDD and iodized salt } \\
\text { utilization }\end{array}$} & Good & 215 & 97 & $2.13(1.50-3.01)$ & $2.25(1.44-3.50)^{* *}$ & 0.001 \\
\hline & Poor & 124 & 119 & 1 & 1 & \\
\hline \multirow{2}{*}{ Storage place in kitchen house } & Near to the fire & 54 & 95 & 1 & 1 & \\
\hline & Away from the fire & 285 & 121 & $4.14(2.78-6.15)$ & $5.09(3.25-7.98)^{* *}$ & 0.001 \\
\hline \multirow{3}{*}{ Where did you buy salt? } & Retail shop & 209 & 103 & $2.32(1.09-4.93)$ & $1.03(0.42-2.51)$ & 0.94 \\
\hline & Open market & 116 & 97 & $1.37(0.64-2.94)$ & $0.68(0.28-1.68)$ & 0.71 \\
\hline & Wholesale & 14 & 16 & 1 & 1 & \\
\hline \multirow{2}{*}{ Distance travel to buy salt } & $<$ or $=1$ hr waking & 263 & 154 & $1.39(0.94-2.06)$ & $0.87(0.49-1.53)$ & 0.62 \\
\hline & $>1 \mathrm{hr}$ waking & 76 & 72 & 1 & 1 & \\
\hline \multirow{2}{*}{ Type of salt } & Packed & 281 & 151 & $2.09(1.39-3.13)$ & $1.89(1.12-3.19)^{*}$ & 0.02 \\
\hline & Bulk & 58 & 65 & 1 & 1 & \\
\hline \multirow{2}{*}{ Used covered container } & Yes & 305 & 178 & $1.92(1.16-3.15)$ & $2.18(1.24-3.81)^{*}$ & 0.01 \\
\hline & No & 34 & 38 & 1 & 1 & \\
\hline \multirow{2}{*}{ Exposed to sun light } & Yes & 40 & 48 & $0.46(0.29-0.74)$ & $0.39(0.23-0.65)^{* *}$ & 0.001 \\
\hline & No & 299 & 168 & 1 & 1 & \\
\hline
\end{tabular}

COR: crude odds ratio, CI: confidence interval, AOR: adjusted OR. * Significant at $P<0.05$ and ${ }^{* *}$ significant at $P<0.01$.

Ethiopia. This could be the result of sunlight (heat) slowly evaporating the iodine content (volatile nature of iodine content) from the HH's use of iodized salt.
4.1. Limitations of the Study. The study's limitation was that the use of iodized salt in retail stores was not measured, and the labeling time was not checked. The impact of clusters 
between urban and rural areas is not being considered. In responding to handling practices, this study was not free of social desirability bias.

\section{Conclusion and Recommendation}

In the district, the proportion of people who use enough iodized salt in their homes is still low. The location of storage, the type of salt purchased, whether the salt was stored in a covered container, and whether the salt was exposed to sunlight have all been identified as significant predictors. As a result, it is necessary to enforce the existing law prohibiting traders from selling unpacked iodized salt and educate the public about how to use iodized salt in the kitchen.

\section{Abbreviations \\ AOR: Adjusted odds ratio \\ CRO: Crude odds ratio \\ EDHS: Ethiopian Demographic and Health Survey \\ HHs: Households \\ IDDs: Iodine deficiency disorders \\ IDTM: Iodometric titration method \\ ppm: Parts per million \\ SPSS: Statistical Package for Social Sciences \\ USI: Universal salt iodization \\ WHO: World Health Organization.}

\section{Data Availability}

The data are available upon request made to the corresponding author via email.

\section{Ethical Approval}

Ethical clearance was obtained from the Ethical Review Board of the Institute of Public Health, University of Gondar.

\section{Consent}

After getting permission from the district to proceed with the study, informed written consent was granted from each study participant. Anyone who was not willing to take part in the study was excluded. Finally, the study did not disclose any information which shows personal identity to assure confidentiality.

\section{Disclosure}

The authors declare that they have no conflicts of interest.

\section{Conflicts of Interest}

The authors declare that they have no conflicts of interest.

\section{Authors' Contributions}

Worku Mamo conceptualized the study. Worku Mamo, Terefe Derso, and Solomon Gedlu Nigatu performed data curation. Worku Mamo, Terefe Derso, and Solomon Gedlu Nigatu were responsible for funding acquisition. Worku Mamo, Terefe Derso, and Solomon Gedlu Nigatu developed methodology. Worku Mamo, Terefe Derso, Solomon Gedlu Nigatu. Resources: Worku Mamo, Terefe Derso, and Solomon Gedlu Nigatu performed project administration. Worku Mamo, Terefe Derso, and Solomon Gedlu Nigatu provided software. Worku Mamo, Terefe Derso, and Solomon Gedlu Nigatu performed supervision. Worku Mamo, Terefe Derso, and Solomon Gedlu Nigatu performed validation. Worku Mamo, Terefe Derso, and Solomon Gedlu Nigatu performed visualization. Worku Mamo, Terefe Derso, and Solomon Gedlu Nigatu wrote the manuscript. Worku Mamo, Terefe Derso, and Solomon Gedlu Nigatu reviewed and edited the article.

\section{Acknowledgments}

The authors would like to thank the study participants and the data collector. Their special gratitude goes to the Ethiopia Public Health Institution.

\section{References}

[1] I. Khurana, A. Khurana, and N. G. Kowlgi, Textbook of Medical Physiology-E-Book, Elsevier Health Sciences, Amsterdam, Netherlands, 2019.

[2] World Health Organization, Assessment of Iodine Deficiency Disorders and Monitoring Their Elimination: A Guide for Programme Managers, World Health Organization, Geneva, Switzerland, 2007.

[3] M. B. Zimmermann, "Iodine deficiency," Endocrine Reviews, vol. 30, no. 4, pp. 376-408, 2009.

[4] United Nations International Children's Emergency Fund, Section UN, Division UP, Communications UDo. Sustainable Elimination of Iodine Deficiency: Progress since the 1990 World Summit for Children, United Nations International Children's Emergency Fund, New York, NY, USA, 2008.

[5] M. R. L. Gizak, J. Gorstein, M. Zimmermann, and M. Andersson, Global Iodine Status in School-Age Children, Women of Reproductive Age, and Pregnant Women in 2017, IODINE Global Network, Kathmandu, Nepal, 2018.

[6] G. Dessie, D. Amare, A. B. Dagnew et al., "Prevalence of goiter among children in Ethiopia and associated factors: a systematic review and meta-analysis," BMC Public Health, vol. 19, no. 1, p. 1191, 2019.

[7] TWB. Group, World Development Indicators 2015, World Bank, Washington, DC, USA, 2015.

[8] A. Singh, S. Gupta, S. Maheshwari, and N. Agrawal, "Status of consumption of iodized salt in rural population in district Bareilly, UP India," International Journal of Current Microbiology and Applied Science, vol. 4, pp. 585-592, 2015.

[9] J. Fisher, T. Tran, B. Biggs et al., "Iodine status in late pregnancy and psychosocial determinants of iodized salt use in rural northern Viet Nam," Bulletin of the World Health Organization, vol. 89, no. 11, pp. 813-820, 2011.

[10] G. N. Khan, I. Hussain, S. B. Soofi, A. Rizvi, and Z. A. Bhutta, "A study on the household use of iodised salt in Sindh and Punjab provinces, Pakistan: implications for policy makers," Journal of Pharmacy and Nutrition Sciences, vol. 2, no. 2, pp. 148-154, 2012 
[11] K. Kazungu, C. M. Mbakaya, and A. Makokha, "Factors contributing to iodide deficiency in coast province of Kenya," European Journal of Research in Medical Sciences, vol. 3, no. 2, 2015.

[12] M. S. Mahfouz, A. M. Gaffar, and I. A. Bani, "Iodized salt consumption in Sudan: present status and future directions," Journal of Health, Population, and Nutrition, vol. 30, no. 4, pp. 431-438, 2012.

[13] C. Nishida, R. Uauy, S. Kumanyika, and P. Shetty, "The joint WHO/FAO expert consultation on diet, nutrition and the prevention of chronic diseases: process, product and policy implications," Public Health Nutrition, vol. 7, no. 1, pp. 245-250, 2004.

[14] A. J. Seal, P. I. Creeke, D. Gnat, F. Abdalla, and Z. Mirghani, "Excess dietary iodine intake in long-term African refugees," Public Health Nutrition, vol. 9, no. 1, pp. 35-39, 2006.

[15] Z. Abebe, A. Tariku, and E. Gebeye, "Availability of adequately iodized in northwest Ethiopia: a cross-sectional study," $A r$ chives of public health =Archives belges de sante publique, vol. 75, p. 33, 2017.

[16] A. A. Desta, U. Kulkarni, K. Abraha, S. Worku, and B. W. Sahle, "Iodine level concentration, coverage of adequately iodized salt consumption and factors affecting proper iodized salt utilization among households in north Ethiopia: a community based cross sectional study," BMC Nutrition, vol. 5 , p. 28, 2019.

[17] S. Hailu, M. Wubshet, H. Woldie, and A. Tariku, "Iodine deficiency and associated factors among school children: a cross-sectional study in Ethiopia," Archives of public health= Archives belges de sante publique, vol. 74, p. 46, 2016.

[18] W. P. Kumma, Y. Haji, J. Abdurahmen, and Y. Mehretie Adinew, "Factors affecting the presence of adequately iodized salt at home in wolaita, southern Ethiopia: community based study," International Journal of Food Science, vol. 2018, no. 3, 9 pages, Article ID 4394908, 2018.

[19] T. C. Mekonnen, S. Eshete, Y. Wasihun, M. Arefaynie, and N. Cherie, "Availability of adequately iodized salt at household level in Dessie and combolcha towns, south wollo, Ethiopia," BMC Public Health, vol. 18, no. 1, p. 1152, 2018.

[20] L. Eden, G. Dereje, Z. Menen, F. Kidist, R. Fikadu, and B. Tafese, "Assessment of handling practices, utilization and concentration of iodine in iodized salt at Wondo Genet town, southern Ethiopia. world journal of innovative research (WJIR)," November, vol. 3, no. I5, pp. 1-7, 2017.

[21] I. Csa, Central Statistical Agency (CSA) [Ethiopia] and ICF. Ethiopia Demographic and Health Survey, Addis Ababa, Ethiopia and Calverton, Addis Ababa, Ethiopia, 2016.

[22] H. G. Gebremariam, M. E. Yesuf, and D. N. Koye, "Availability of adequately iodized salt at household level and associated factors in Gondar town, northwest Ethiopia," ISRN Public Health, vol. 2013, Article ID 160582, 6 pages, 2013.

[23] B. Gidey, K. Alemu, A. Atnafu, M. Kifle, Y. Tefera, and H. Sharma, "Availability of adequate iodized salt at household level and associated factors in rural communities in Laelay Maychew district, northern Ethiopia: a cross sectional study," Journal of Nutrition Health Science, vol. 2, no. 1, p. 1, 2015.

[24] L. Takele, T. Belachew, and T. Bekele, "Iodine concentration in salt at household and retail shop levels in Shebe town, south west Ethiopia," East African Medical Journal, vol. 80, no. 10, pp. 532-539, 2003.

[25] M. S. Mahfouz, A. M. Gaffar, and I. A. Bani, "Iodized salt consumption in Sudan: present status and future directions," Journal of Health, Population, and Nutrition, vol. 30, no. 4, pp. 431-438, 2012.
[26] J. R. Khan, R. K. Biswas, M. T. Sheikh, and M. Huq, "Factors associated with the availability of iodized salt at household level: a case study in Bangladesh," Public Health Nutrition, vol. 22, no. 10, pp. 1815-1823, 2019.

[27] C. S. Pandav, N. K. Arora, A. Krishnan, R. Sankar, S. Pandav, and M. G. Karmarkar, "Validation of spot-testing kits to determine iodine content in salt," Bulletin of the World Health Organization, vol. 78, no. 8, pp. 975-980, 2000.

[28] N. Demographic, Health Survey 2011. Addis Ababa, Ethiopia, Central Statistical Agency, Addis Ababa, Ethiopia, 2012.

[29] P. L. Jooste, M. J. Weight, and C. J. Lombard, "Iodine concentration in household salt in south Africa," Bulletin of the World Health Organization, vol. 79, no. 6, pp. 534-540, 2001.

[30] M. V. Mannar, J. T. Dunn, M. Initiative, Disorders I.CfCoI.D, and United Nations International Children's Emergency Fund, Salt Iodization for the Elimination of Iodine Deficiency, International Council for Control of Iodine Deficiency Disorders, NY, NY, USA, 1995.

[31] N. J. Aburto, M. Abudou, V. Candeias, T. Wu, and World Health Organization, Effect and Safety of Salt Iodization to Prevent Iodine Deficiency Disorders: A Systematic Review with Meta-Analyses, World Health Organization, Geneva, Switzerland, 2014.

[32] L. Dahl, A. Duinker, S. Næss et al., "Iodine and mercury content in raw, boiled, pan-fried, and oven-baked atlantic cod (Gadus morhua)," Foods, vol. 9, no. 11, p. 1652, 2020.

[33] P. K. Dasgupta, Y. Liu, and J. V. Dyke, "Iodine nutrition: iodine content of iodized salt in the United States," Environmental Science \& Technology, vol. 42, no. 4, pp. 1315-1323, 2008.

[34] R. Rana and R. S. Raghuvanshi, "Effect of different cooking methods on iodine losses," Journal of Food Science and Technology, vol. 50, no. 6, pp. 1212-1216, 2013.

[35] B. Mesfin, B. Misganaw, M. T. Hunegnaw, and E. A. Muhammad, "Goiter and its associated factors among adolescent high school girls at Tach Armachiho district, northwest Ethiopia: an institution-based cross-sectional study," Journal of Nutrition and Metabolism, vol. 2020, no. 3, 7 pages, Article ID 3695952, 2020.

[36] E. Tigabu, K. B. Bekele, and B. A. Dachew, "Prevalence of goiter and associated factors among schoolchildren in northeast Ethiopia," Epidemiology and Health, vol. 39, Article ID e2017055, 2017.

[37] H. Mushary, H. Haridi, B. M. A. Bashir, A. M. A. Shangiti, S. A. Shehri, and I. Hussein, "Assessment of household use of iodized salt and adequacy of salt iodization: a cross-sectional national study in Saudi Arabia," Nutrition Journal, vol. 17, p. 35, 2018.

[38] S. Khatiwada, B. Gelal, M. K. Tamang et al., "Iodized salt use and salt iodine content among household salts from six districts of eastern Nepal," Journal of Nepal Health Research Council, vol. 12, no. 28, pp. 191-194, 2014.

[39] Z. Ahmed, Z. Meriem, and T. Jamal, "Assessment of iodine concentration in dietary salt at household level in Morocco," BMC Public Health, vol. 16, p. 418, 2016.

[40] S. Hawas, S. Lemma, S. Mengesha, H. Demissie, and M. Segni, "Proper utilization of adequatly iodized salt at house hold level and associated factores in Asella town arsi zone Ethiopia," Journal of Food Processing and Technology, vol. 7, p. 573, 2016.

[41] Z. A. Anteneh, M. Engidayehu, and G. Abeje, "Iodine content of dietary salt at household level and associated factors using Iodometric titration methods in Dera district, northwest Ethiopia," BMC Nutrition, vol. 3, p. 83, 2017. 
[42] Ethiopian Food and Drug Authority, Iodized Salt Directive Addis Ababa, Ethiopian Food and Drug Authority, Addis Ababa, Ethiopia, 2011.

[43] T. Masresha, H. Dejene, and Z. Menen, "Availability and utilization of adequately iodized salt by urban and rural households and associated factors in southern Ethiopia, sidama zone, Bensa woreda," International Journal of Food Science and Nutrition Engineering, vol. 6, no. 3, pp. 62-71, 2016.

[44] A. Bhatnagar, N. S. Maharda, V. K. Ambardar, D. N. Dham, M. Magdum, and R. Sankar, "Iodine loss from iodised salt on heating," The Indian Journal of Pediatrics, vol. 64, no. 6, pp. 883-885, 1997.

[45] B. Anteneh, B. Negga, and S. Berhanu, "Availability of adequately iodized salt at household level and associated factors in dire dawa, eastern Ethiopia," International Journal of Public Health Science (IJPHS) December, vol. 5, no. 4, pp. 392-399, 2016.

[46] A. Kalu Tololu, "Coverage of iodized salt and associated factors at household level in Goba town, bale zone, south east Ethiopia, 2015," Science Journal of Public Health, vol. 4, no. 4, pp. 346-351, 2016. 